\title{
La Confederación Campesina: Un sindicato agrícola líder del movimiento altermundialista francés. Análisis de una situación paradójica*
}

\author{
Ivan Bruneau**
}

\begin{abstract}
Resumen
Este artículo restituye el proceso que condujo a la inscripción de la Confederación Campesina (un sindicato agrícola francés, CC) en el movimiento altermundialista a fines del año 1999. En una primera parte, después de una breve presentación del registro protestatario construido durante los años setenta y ochenta, el autor pone énfasis en la reproblematización de lo "internacional" que sucede a la reforma de la Política Agrícola Común (PAC) de 1992. Este razonamiento genealógico le permite especificar las condiciones de posibilidad de la acción de desmontaje del Mc Donald's de Millau en agosto de 1999. La segunda parte analiza los efectos contradictorios producidos por la intensa mediatización de aquella acción y busca comprender las diferentes tomas de posición en los debates internos acerca de las virtudes y límites del combate altermundialista.
\end{abstract}

Palabras clave: Sindicalismo agrícola - altermundialismo - framing de "lo internacional" - trayectorias biográficas - retribuciones simbólicas de la militancia.

\begin{abstract}
The paper analyses the very special process which led the Confédération Paysanne (CP) to become part of the antiglobalization movement. In the first part, after a brief introduction to the specific range of radical protest against the Common Agricultural Policy (CAP) in the seventies and in the eighties, the author describes the inward outcomes of the 1992 CAP reform. And he tries to put on a local viewpoint the démontage of the Mc Donald's restaurant in Millau (August 1999) which was the beginning of the obvious involvement of the $C P$ at the heart of the antiglobalization movement. The second part deals with the post-Millau events and discusses the contradictory effects of the new visibility in the media of the CP claims.
\end{abstract}

Keywords: Agricultural syndicalism - antiglobalization - international framing - biographical trajectories - symbolic retributions of militancy.

* El presente artículo es una versión modificada de otro publicado en la revista Politix (Bruneau, 2004). Se enmarca en el Proyecto de Investigación ECOS-CONICYT C05H01. Agradecemos a Diana Hochraich por la traducción. Los resultados de una encuesta realizada en el marco de nuestra tesis de doctorado (Bruneau, 2006) han servido de base a la redacción de este artículo. La investigación sobre el activismo en la Confederación Campesina recurre a tres tipos de datos: unas cincuenta entrevistas semidirectivas, la observación etnográfica de diversas situaciones (congresos nacionales, reuniones en los departamentos del Orne y del Aveyron, manifestaciones, etc.), y la explotación de los archivos de la estructura nacional y de los sindicatos del Orne y del Aveyron.

** Profesor asistente de Ciencia Política de la Universidad de Lyon 2, Francia, e Investigador del Laboratorio de Estudios Rurales (LER). Correo electrónico: bruneau.ivan@gmail.com 
En Francia, los observadores de la vida política reconocen el papel que juega la Confederación Campesina (CC) (Confédération Paysanne) en la afirmación del movimiento altermundialista. Entre 1999 y 2003, este sindicato agrícola, claramente de izquierda, no sólo ha participado en diferentes reuniones de la nebulosa contestataria, sino que también ha promovido acontecimientos ampliamente mediatizados. El 12 de agosto de 1999, en el departamento del Aveyron ${ }^{1}$, los militantes de la CC se reúnen delante del McDonald's y proceden al "desmontaje" del edificio que estaba en construcción ${ }^{3}$. En pleno verano, esta acción sindical ocupa la portada de los diarios. La mediatización es amplificada por la detención provisoria del líder departamental del sindicato, José Bové. Muy rápidamente, las organizaciones de izquierda (partidos políticos, centrales sindicales, asociaciones) denuncian la "represión" y apoyan la causa defendida por José Bové y sus camaradas. Los activistas de la CC justifican su acción porque la consideran como una crítica radical hacia la Organización Mundial del Comercio (OMC). En efecto, unos meses antes la OMC había autorizado al gobierno americano aumentar el arancel aduanero de las importaciones de varios productos europeos $^{4}$, entre los cuales figuraba el queso roquefort, que estaba incluido en la lista de productos gravados con un $100 \%$. En el departamento del Aveyron se encuentran muchos criadores de ovejas que producen leche para la fabricación de este queso. La acción en contra del McDonald's tenía por objeto establecer una relación directa entre la situación de los agricultores locales y la evolución global de las reglas comerciales. En noviembre de 1999, durante la reunión cumbre de la OMC en Seattle, José Bové ocupa las primeras filas de la manifestación, sus intervenciones llaman la atención y se impone como portavoz de esta dinámica contestataria. El 30 de junio del 2000, día del proceso de los diez activistas inculpados por el "desmontaje" del McDonald's, más de 100.000 personas llegan a Millau para afirmar su solidaridad con las luchas de la CC.

Así, en unos meses, este sindicato agrícola adquirió una posición central dentro del movimiento de oposición a la "mundialización liberal". En Francia esta situación es por lo menos paradójica porque parece contradecir la historia reciente de una profesión designada generalmente como "corporativa" y "conservadora". La paradoja es todavía más sorprendente si se tiene en cuenta que los agricultores representan hoy en día sólo el $2 \%$ de la población activa y que la CC, desde su creación en 1987, ha tenido siempre una presencia minoritaria en la profesión ${ }^{5}$. El hecho de que ese sindicato agrícola se encuentre en la posición de responder a las expectativas de una nebulosa política compuesta esencialmente por activistas exteriores a ese medio profesional suscita interrogantes. Este compromiso altermundialista,

1 El departamento del Aveyron se sitúa en el sur de Francia y forma parte de la región Midi-Pyrenées. La ciudad de Millau (alrededor de 15.000 habitantes), subprefectura del Aveyron, está en el sur del departamento, cerca de la meseta de Larzac.

2 Para evitar toda confusión con nuestras propias expresiones, las declaraciones de los actores que figuran en el cuerpo del texto serán sistemáticamente escritas en letra cursiva.

La inauguración estaba prevista para el mes de septiembre.

4 Esta decisión del gobierno americano vino después de que la Unión Europea prohibiera la importación de carne vacuna con hormonas.

5 La CC ha obtenido sus mejores resultados en las elecciones profesionales de enero del 2001, cuando recogió el $26 \%$ de los sufragios. A principios del año 2000, el sindicato contaba con alrededor de 10.000 miembros. 
¿es el resultado de una ruptura o de un deslizamiento ideológico? ¿En qué momento de la historia interna de la organización, interviene el "desmontaje" del McDonald's de Millau? Por último, ¿en qué medida las consecuencias políticas y mediáticas de esta acción han modificado la relación de fuerzas entre las diferentes corrientes del sindicato? Sólo se pueden responder esas preguntas tratando de reconstituir las etapas del proceso que han conducido a la inscripción de la CC en el centro del movimiento altermundialista.

\section{UNMOMENTO SINGULAR EN UNA HISTORIA ESPECÍFICA. PROBLEMAS DE MÉTODO}

Desde fines de 1999, la CC crece en notoriedad. Desde su creación en 1987, el sindicato nunca había sido tan solicitado políticamente, ni expuesto a los medios de comunicación, ni reconocido públicamente. Ese cambio de imagen se explica por el surgimiento de un portavoz particularmente eficaz en la persona de José Bové 6 . Desconocido del gran público antes de la acción de Millau, José Bové adquiere inmediatamente un gran renombre, que va más allá de su sector profesional. Siendo invitado regularmente a programas políticos, este personaje mediático aparece rápidamente como la figura emblemática del movimiento de oposición a la mundialización. Hay pocos ejemplos, en la vida política francesa, de una asociación tan estrecha entre el desarrollo de una causa y su encarnación en un personaje público.

\subsection{José Bové, activista inclasificable y profeta del altermundialismo}

A fines de 1999, los franceses descubren a un agricultor que no se parece al medio social al que supuestamente debe representar. José Bové no tiene un "acento campesino", habla inglés con fluide $z^{7}$, no recarga su discurso con sutilezas técnicas y domina perfectamente las reglas del lenguaje político. Como sus tomas de posición no se reducen a cuestiones agrícolas, el líder sindical trastorna todavía más las lógicas ordinarias de clasificación. Toma por ejemplo partido a favor de los palestinos ${ }^{8}$, denuncia el sistema carcelario francés que, según él, es indigno del "país de los Derechos Humanos". Es como si la multiplicación de esos indicios disonantes contribuyera a hacer de José Bové un activista inclasificable, "cuyos comportamientos excéntricos y extraños pueden ser admirados por estar fuera de lo común o despreciados por falta de sentido común" (Bourdieu, 1971: 318). En un momento de crisis de propuestas políticas, un público activista amplio adhiere a la ruptura que produce esta palabra profética. Claramente, José Bové logra responder a las expectativas que él mismo

6 Después del desmontaje del McDonald's de Millau, los periodistas presentan a José Bové como el "portavoz" o el "presidente" del sindicato, aunque no ejercía en éste más responsabilidades desde 1996. Después de unos meses de duda, los responsables nacionales deciden poner fin a esta situación y organizan su "retorno" al seno de las instancias nacionales. En abril del 2000, en el Congreso de Argentan, José Bové es elegido como miembro del Secretariado Nacional, donde se lo designa como "portavoz a cargo de los asuntos internacionales".

7 Durante su infancia, vivió unos años en los Estados Unidos. José Bové no es originario del mundo agrícola, sus padres eran investigadores en biología vegetal del Instituto Nacional de la Investigación Agronómica (Institut National de la Recherche Agronomique, INRA). Volveremos a evocar su trayectoria más adelante en este artículo.

8 En la primavera de 2002, viaja a Ramallah y participa en una Misión de Protección del Pueblo Palestino. 
contribuye a crear. En agosto del 2003, unos días después de haber salido de la cárcel ${ }^{9}$, más de 200.000 personas participan en el gran mitin "antiliberal" organizado en la meseta de Larzac. Al día siguiente, el periódico Libération, dada la amplitud de ese movimiento de opinión, califica a José Bové como el "opositor № 1"10 al gobierno. Sin embargo, por más espectacular que sea este movimiento, no alcanza a explicar el compromiso de la CC con el altermundialismo. En efecto, no se puede disociar la emergencia de ese liderazgo del proceso organizativo que lleva a José Bové a aparecer como un portavoz legítimo. Para reconstruir esta historia, hay que interesarse por la manera en que la $\mathrm{CC}$ ha tomado en cuenta "lo internacional", transformándolo en un tema central de su combate sindical.

\section{2. "Lo internacional" como tema central del combate sindical}

Durante los últimos veinte años los agricultores franceses han sido confrontados a la extensión de los mercados agrícolas, que ha acentuado la competencia a la que han sido sometidas sus producciones. Sin embargo, esta "mundialización" parece corresponder a las últimas inflexiones de un proceso que se inscribe en el largo plazo. En efecto, la lectura de los trabajos sobre las políticas agrarias revela que las salidas de la producción hacia otros mercados constituyen una cuestión permanente. Desde el principio de los años sesenta, la creación de la Política Agrícola Común (PAC) permitió desarrollar relaciones comerciales entre los países miembros de la Comunidad Económica Europea (CEE) y aumentar el volumen de las exportaciones hacia otras partes del mundo. En consecuencia, y aunque ciertas evoluciones políticas hayan contribuido a acentuar esta internacionalización de los intercambios (volveremos sobre este punto), no se trata de un fenómeno reciente, que se habría impuesto "inopinadamente" a los agricultores franceses. En otras palabras, la implicación altermundialista de la CC no puede ser considerada como el resultado "lógico" de una adaptación a una nueva situación económica. Por otra parte, si se adopta ese tipo de explicación no puede entenderse por qué los otros sindicatos agrícolas han preferido mantenerse al margen del movimiento de contestación, salvo si se supone, mediante un razonamiento absurdo, que sólo los activistas de la CC habrían sido "afectados" directamente por las consecuencias de la "mundialización". Por esta razón, hay que modificar el foco de análisis para incorporar las "construcciones intelectuales" (Agrikoliansky et al., 2005: 42) que han precedido y acompañado la emergencia de una retórica altermundialista.

Para develar ese trabajo de "encuadre" (framing) de la situación (Snow, 2001), debemos inscribir el momento altermundialista de la CC en una historia de los usos internos de "Io internacional". Esta noción es entendida aquí no solamente como el espacio en el que se toman las decisiones de política agrícola; "lo internacional" constituye también una dimensión

9 En julio del 2003, José Bové es encarcelado durante cinco semanas por encabezar una operación de destrucción de una reserva de semillas de maíz transgénico. El año anterior, en julio del 2002, había purgado una primera pena de prisión tras ser considerado por la justicia como el "instigador" de la acción en contra del McDonald's de Millau.

10 Primera plana del diario Libération, el 11 de agosto del 2003. 
de la reflexión y de la acción sindical, a la que los activistas conceden una importancia variable. El lugar ocupado por "lo internacional" en la producción de las reivindicaciones depende en gran parte de la evolución de las relaciones de fuerza dentro de la organización. Como veremos, la crítica hacia la "mundialización" ha sido representada en primer lugar por los activistas que han tratado de imponer ese recurso en las luchas por la definición de una "línea" dominante.

\subsection{Tomar la medida del "acontecimiento": agosto de 1999 y el desmontaje del McDonald's de Millau}

En Francia se considera generalmente al movimiento social de diciembre de 1995 como uno de los momentos fundadores de la nebulosa altermundialista ${ }^{11}$. Sin embargo, para analizar la CC y su inscripción en esta dinámica es necesaria otra periodización. En primer lugar, las prolongaciones de la acción de Millau han modificado la naturaleza de las relaciones del sindicato con las otras organizaciones que componen el "movimiento". Después del "desmontaje" del McDonald's, los responsables de la CC alegan tres tipos de rechazo: la lucha contra la OMC y las multinacionales, el rechazo de la agricultura industrial y de una alimentación aséptica y normalizada12, y la denuncia de la "represión sindical". Ese discurso permite múltiples convergencias y la CC puede entonces apoyarse en una movilización amplia, sobre la base de lógicas de alianza relativamente heterogéneas. Cuando José Bové y otros activistas se ven de nuevo implicados en procesos judiciales, esta solidaridad se encuentra sistemáticamente confirmada. Sin embargo, más allá de esta aparente continuidad, los apoyos puntuales se van transformando progresivamente en solicitaciones explícitas, ya que las organizaciones del "movimiento social" esperan aprovechar la capacidad de la CC para representar la oposición a la mundialización. Esto es justamente lo que subrayaba uno de nuestros entrevistados, miembro del Secretariado Nacional, en octubre del 2002:

"En un primer momento, no habíamos evaluado suficientemente lo que se esperaba de la Conf' (la CC), tal vez eso sea menos cierto actualmente, porque las otras estructuras sindicales están adquiriendo mayor peso, pero la Conf' era verdaderamente la estructura que destacaba en este movimiento social, la gente se reconocía en una acción, a través de una persona, José (Bové), se esperaba mucho de la Conf', y se esperaba cada vez más de la Conf', (...) con la posición que tenemos sobre la agricultura, sobre la soberanía alimenticia, sobre la importancia de la agricultura y el estatus de los campesinos, naturalmente esa gente se torna hacia nosotros, en fin 'retornan', están esperando actos de solidaridad y de presencia.

¿Hay demasiada demanda, de cierta manera?

Eh, sí, hay demasiada demanda..., no necesariamente, pero es cierto que no siempre es fácil responder a todo, y a veces tu compromiso se limita únicamente a firmar un texto, un volante, para mí, es lo mínimo que podemos hacer, pero no es suficiente, y nosotros también

11 Sobre este punto, véase el análisis de Jean-Gabriel Contamin (2005) así como el artículo de Boris Gobille (2008) publicado en este mismo volumen.

12 Lo que José Bové designa entonces con la expresión de "malbouffe". Véase Bové y Dufour (2000). 
estamos en posición de demanda hacia esa gente cuando tenemos procesos, cuando un portavoz está en la cárcel, cuando queremos pelear contra la PAC (...)".

El sindicato debe responder a numerosos pedidos que le llegan, sin haber estado preparado para asumir esa responsabilidad. En la estructura nacional, esta "aceleración de la historia" se traduce en un fuerte aumento de los empleados y en tentativas de racionalización de las tareas militantes ${ }^{13}$. Paralelamente, la implicación en la dinámica altermundialista introduce flexibilidad en el equilibrio de las relaciones de fuerza y el nuevo estatus de "lo internacional" cristaliza las divergencias. En el 2002, un conflicto opone a los representantes de dos "tendencias" y los activistas son invitados a elegir entre dos estrategias sindicales. En ese sentido, la acción de Millau es indiscutiblemente un "acontecimiento" pues a fines del año 1999 los activistas inscriben su compromiso en una "nueva temporalidad, que modifica las relaciones con el pasado y con el futuro" (Bensa y Fassin, 2002: 11). Sin embargo, las percepciones del "acontecimiento" dependen en gran medida del proceso que, al crear ciertas condiciones, lo ha hecho posible. Por esta razón, organizaremos nuestro análisis en torno a ese momento clave.

\section{EL "DESMONTAJE" DEL MCDONALD'S DE MILLAU, RESULTADO DE UNA REPROBLEMATIZACIÓN Y DE UNA “LOCALIZACIÓN" DE “LO INTERNACIONAL"}

El compromiso altermundialista de la CC es el resultado inestable de una redefinición de "lo internacional", consecutiva a la reforma de la PAC de 1992. En agosto de 1999, la acción de Millau, que se inscribe en una configuración local original, constituye una de las expresiones significativas de esos desplazamientos de "lo internacional". Sin embargo, de la misma manera que no se puede comprender el altermundialismo sin restituir "la larga historia de esta nueva causa"14, es importante resituar ese momento en una historia más antigua, cuyo origen es anterior a la creación del sindicato.

\subsection{Los procesos de framing de "lo internacional" en los años setenta y ochenta. Búsqueda de los orígenes y razonamiento genealógico}

En 1987, el "nacimiento" de la CC resulta de la fusión de dos organizaciones creadas a principios de los años ochenta, la Confederación Nacional de Sindicatos de Trabajadores Campesinos (Confédération Nationale des Syndicats des Travailleurs Paysans, CNSTP) y la Federación Nacional de Sindicatos Campesinos (Fédération Nationale des Syndicats Paysans, FNSP), dos organizaciones que tuvieron su origen en los movimientos contestatarios surgidos después de los acontecimientos de mayo de $1968^{15}$. A principios de los años

13 En la CC no existen los activistas asalariados por el sindicato con estatus de "permanente". Los asalariados de la estructura nacional no son agricultores, trabajan en la sede de la CC, en Bagnolet, en la región parisina. Entre fines de 1999 y fines del 2001 el sindicato ha contratado a unos diez asalariados, lo que significa un aumento considerable, ya que en agosto de 1999 el sindicato sólo contaba con veinte personas contratadas.

14 Véase Agrikoliansky et al. (2005).

15 Sobre la historia de la contestación de mayo de 1968, véase Bruneau (2008). 
setenta, en el seno de los sindicatos mayoritarios -la Federación Nacional de Agricultores (Fédération Nationale des Syndicats d'Exploitants Agricoles, FNSEA) y el Centro Nacional de Jóvenes Agricultores (Centre National de Jeunes Agriculteurs, CNJA)-, unos "campesinos de izquierda" oponen sus propias orientaciones a aquellas que defienden sus directivas. Estas corrientes disidentes se van a estructurar, y a principios de los años ochenta pasarán a constituir sindicatos autónomos.

Desde fines de los años sesenta, la historia de esta izquierda campesina se caracteriza por una oposición constante a la lógica económica que impone la PAC. En 1970, en su libro Les paysans dans la lutte des classes, Bernard Lambert, líder del movimiento CampesinosTrabajadores (Paysans-Travailleurs), escribe que la política europea "conduce a la integración total del sector agrícola en el modo de producción capitalista" (Lambert, 1970: 87). Igualmente, en diversas ocasiones en los años setenta, el periódico de los Campesinos-Trabajadores, Vent d'Ouest, acusa a los responsables políticos europeos de favorecer la apropiación de la plusvalía contenida en el trabajo agrícola por "las empresas" que proveen los insumos a la agricultura y por las que utilizan como insumos la producción agrícola. De igual modo, en 1982, los activistas de la FNSP constatan que en "la Europa de los Estados asociados, la Comunidad de intereses de los trabajadores europeos que algunos anunciaban, han sido sacrificados a favor de un magma mercantil, llamado Europa de los comerciantes, supervisado y dirigido por una tecno-estructura cuyas decisiones y orientaciones escapan continuamente todo control político real"16. Además, desde el principio de los años setenta, los agricultores influenciados por los acontecimientos de mayo de 1968 establecen una relación objetiva entre las políticas agrícolas occidentales y las desigualdades estructurales de los intercambios norte-sur. En 1985, los activistas de la CNSTP denuncian el carácter "imperialista" del "productivismo" occidental, en la medida en que refuerza "la dependencia de los pueblos del sur respecto a las economías del norte"17. En 1987, al momento de la creación de la CC, los primeros responsables de la organización inscriben "la autosuficiencia alimenticia de los pueblos del Tercer Mundo" entre los seis objetivos que asignan a la política agrícola que reivindican ${ }^{18}$.

Está claro que la crítica a la mundialización, tal como se ha mediatizado después del "desmontaje" del McDonald's de Millau, no surge de "la nada", no es una "invención total". Sin embargo, esta búsqueda de los orígenes, indispensable cuando se desea neutralizar la ilusión de "novedad absoluta", o de "jamás visto", tiende mecánicamente a detectar la presencia del "ya existía" en lo que justamente no existía aún y, de hecho, a presentar una historia hecha de anacronismos. Es por eso que Michel Foucault opera una distinción entre "la búsqueda de los orígenes" y "la genealogía" e invita a "detectar los accidentes, las desviaciones ínfimas" en una historia que puede parecer a primera vista coherente y

$16 \quad 1^{\text {er }}$ Congreso de la FNSP, París, 16-17 noviembre de 1982, Informe "Un revenu minimum garanti pour tous les paysans" (Un ingreso mínimo garantizado para todos los campesinos), pp. 5-6.

17 Congreso de la CNSTP, Villeneuve-sur-Lot, 10-11 abril 1985, Informe de orientación “Combien de paysans avec quel revenu. Un choix qui interpelle toutes les forces sociales" (Cuántos campesinos y con qué ingreso. Una elección que interpela a todas las fuerzas sociales), p. 51.

18 Documento de presentación de la CC, abril de 1987. 
lineal (Foucault, 2001: 1009). Para entender cómo la CC ha podido, en un momento dado y en una forma precisa, devenir "altermundialista", hay que concentrar el análisis en un período más corto, durante el cual el trabajo de definición de "lo internacional" dio lugar a posiciones conflictivas.

\subsection{Los desplazamientos de "lo internacional": la reforma de la PAC de 1992 y sus repercusiones internas}

En los años ochenta, debido a la acumulación de excedentes agrícolas, las reformas de la PAC consisten esencialmente en la adopción de dispositivos para controlar el volumen de la producción europea. En 1984, la instauración de cuotas de producción de leche de vaca constituye una ilustración perfecta de esta política de "contingentación de la oferta". Sin embargo, esas medidas no amenazaban al sistema de "precios garantizados", que eran "el instrumento central de la regulación de los mercados agrícolas" (Fouilleux, 2003: 21) ${ }^{19}$. En cambio, la reforma de 1992 modifica las condiciones, al imponer una disminución del 30\% del precio garantizado en el sector de los cereales y del $15 \%$ en el de la carne vacuna. Esas disminuciones de precio son compensadas parcialmente con ayudas directas al productor, cuyo monto depende de las superficies cultivadas. Para los activistas de la CC, la "PAC 92", que expone todavía más la producción europea a la competencia de un "precio mundial", está condicionada por las negociaciones del GATT (General Agreement on Tariffs and Trade, "antepasado" de la OMC). La "integración de la PAC en el GATT" modifica las percepciones sobre "lo internacional". Esta nueva instancia de decisiones les parece lejana, opaca y "antidemocrática" y la asimilan rápidamente a la voluntad de dominación de Estados Unidos y de las empresas multinacionales ${ }^{20}$. El cambio de escala del combate sindical conduce a la CC a participar en la creación en 1993 de "Vía Campesina", una "Internacional campesina" que agrupa organizaciones europeas, asiáticas y latinoamericanas. Por otra parte, en la medida en que las negociaciones del GATT introducen reglas comerciales no específicas a la agricultura, la CC puede fundar su oposición a la reforma de la PAC en el análisis de una evolución más general y, de esta manera, proponer un encuadre (framing) de la situación que conduzca a una repolitización de la cuestión de los precios agrícolas. Esta "desectorialización" ${ }^{21}$ del discurso sindical constituye una condición previa a su inscripción en una movilización más amplia. Así, el 4 de diciembre de 1993, los activistas de la CC participan en la manifestación

19 A principios de los años sesenta, para mantener los precios europeos a un nivel equivalente a los del mercado mundial, la PAC avanza el principio de la "preferencia comunitaria", sobre la base de la instauración de un arancel aduanero exterior común y la introducción de un sistema de retenciones/restituciones: "Se opera una retención variable sobre los productos de un país exterior a la Comunidad Europea, de un monto equivalente a la diferencia entre el precio mundial y el de sostén. El arancel aduanero funciona como un impuesto, destinado a disuadir las importaciones y a evitar la invasión del mercado por materias primas agrícolas producidas en el resto del mundo. Paralelamente, las restituciones a la exportación permiten a los productores de la Comunidad exportar sus productos a países exteriores a la Comunidad a precio mundial, percibiendo el precio europeo garantizado, puesto que el presupuesto de la Comunidad paga la diferencia" (Fouilleux, 2003: 14).

20 Ver el "Rapport d'orientation de l'Assemblée Générale de Lyon" (Informe de orientación de la Asamblea General de Lyon) de diciembre de 1992.

21 Sobre la noción de "desectorialización", véase Michel Dobry (1992). 
organizada en Ginebra por la asociación "Actuar para una alternativa al GATT" (Agir pour une alternative au GATT) donde se suman a campesinos de otros continentes y también a activistas ecologistas y tercermundistas con quienes desfilan ${ }^{22}$. Es igualmente en este período que tiene lugar el encuentro con "intelectuales", universitarios y periodistas -los del periódico Le Monde Diplomatique y de Politis por ejemplo- conocidos por sus análisis críticos sobre el proceso de difusión del "neoliberalismo" a escala mundial.

Esta descripción de los desplazamientos de "lo internacional" no es plenamente satisfactoria, ya que tiende a acentuar la homogeneidad del colectivo activista y a presentar la imagen de "una totalidad unificada y reificada" (Offerlé, 1997: 10). En realidad, en 1992, no todos los miembros de la CC reaccionan de la misma manera frente a la reforma de la PAC. En general, los activistas están convencidos de haber sido engañados por los responsables políticos. En efecto, el informe previo, redactado bajo la autoridad del Comisario Europeo de Agricultura, formulaba propuestas que parecían concordar con el proyecto sindical, pero las diferencias entre ese informe (Informe Mac Sharry) y el contenido de la reforma finalmente anunciada dan lugar a un sentimiento de fracaso. En ese contexto, varios responsables departamentales ${ }^{23}$, entre los cuales muchos miembros del Comité Nacional (instancia de decisión de la $\mathrm{CC})^{24}$, critican la actitud del Secretariado Nacional ${ }^{25}$ reprochándole haber tratado de "negociar", con el objetivo ilusorio de "suavizar" los efectos de la reforma ${ }^{26}$. En una etapa posterior, mientras la mayoría del Comité nacional expresa su desacuerdo con esa iniciativa, deciden participar en las reuniones y acciones de la Coordinación rural, una coalición "intersindical" creada por un antiguo responsable departamental de la FNSEA para reunir a los agricultores que se oponen a la "Nueva PAC"27. A partir de ese momento, las divergencias iniciales se endurecen en un clivaje estructurante, regularmente alimentado por las múltiples "maniobras y contramaniobras" (Dobry, 1992: 21) de parte de los miembros de ambas "tendencias". La estrategia adoptada frente a la reforma de la PAC sólo constituye uno de los elementos de la crítica desarrollada por los "radicales". Este grupo minoritario, al

22 En Ginebra, los activistas de la CC desfilan bajo la bandera de la Coordinación Campesina Europea (CPE). Creada en 1987, la CPE ha sido concebida como un grupo de presión susceptible de disputar el monopolio de la representación agrícola europea que posee el Comité de las Organizaciones Profesionales Agrícolas (Comité des Organisations Professionnelles Agricoles, COPA), en el cual la FNSEA, el sindicato mayoritario en Francia, juega un rol preponderante.

23 En las regiones Languedoc-Roussillon y Poitou-Charentes, en los departamentos del Aveyron, del Puy-de-Dôme y de la Manche.

24 El Comité Nacional está compuesto por delegados elegidos por las estructuras regionales de la CC. Se reúne una vez al mes en la sede del sindicato.

25 El Secretariado Nacional, compuesto de una decena de miembros, es elegido por el Comité Nacional. El Secretariado Nacional es considerado como la instancia "ejecutiva" de la CC. El mandato de Secretario Nacional implica una presencia semanal en la sede del sindicato (tres a cuatro días por semana).

26 Aquí nuestro análisis se sustenta en los informes de las reuniones del Comité Nacional entre 1992 y 1996.

27 En 1992 y 1993 esta Coordinación reúne a los activistas de algunas estructuras departamentales de la FNSEA, del Movimiento de Defensa de las Explotaciones Familiares (Mouvement de Défense des Exploitations Familiales, $M O D E F$ - un sindicato bien implantado en el sudoeste, cuyos responsables son frecuentemente miembros o simpatizantes del Partido Comunista- y de la Federación Francesa de la Agricultura (Fédération Française de l'Agriculture, F.F.A.), otro sindicato minoritario, cuyos miembros, al contrario, se ubican claramente a la derecha o extrema-derecha del espectro político. 
que pertenece José Bové, trata de imponer su punto de vista sobre "la crisis" del sindicato, aplicándose a definir su naturaleza y a determinar su importancia. Así, en la reunión del Comité Nacional del 19 y 20 de abril de 1994, uno de ellos justifica así sus posiciones: "La confederación, muy afectada por la PAC y el GATT, ha fracasado en su estrategia ofensiva. Una parte importante de la Confederación Campesina quería actuar, pero no hemos sabido crear un movimiento social fuerte" 28 . En 1995, en el Congreso de Montmorillon, los líderes de esta "tendencia" logran hacer elegir tres de sus representantes en el Secretariado Nacional, lo que contribuye a calmar las tensiones entre los dos grupos. Sobre todo, ese compromiso organizacional constituye un momento importante en la historia de los usos internos de "lo internacional" en el seno de la CC. Eso permite especialmente a François Dufour y a René Riesel acceder al Secretariado Nacional. Ambos activistas, cercanos a José Bové, no tienen la misma trayectoria, pero van a participar juntos en la redefinición de la situación política. Según ellos, el sindicato no puede confinarse en sus propios objetivos, la defensa "profesional" de los agricultores franceses no puede disociarse de la lucha contra la difusión de un modelo económico a escala internacional. François Dufour nació en 1953, fue miembro de la dirección nacional de la CNSTP en los años ochenta, es productor de leche de vaca en el departamento de la Manche, al noroeste del país. En 1995, es nombrado portavoz nacional de la CC. Forma parte de los que involucran a la organización en una crítica radical de la OMC. En agosto de 1999, después del "desmontaje" del McDonald's de Millau, sus múltiples intervenciones públicas sitúan explícitamente al sindicato en el movimiento de oposición a la mundialización "liberal". En el 2000, al final de su mandato como secretario nacional de la CC, es elegido vicepresidente de la asociación ATTAC ${ }^{29}$. A diferencia de François Dufour, René Riesel, nacido en 1950, no es hijo de agricultores. Estudiante de filosofía en la Universidad de Nanterre en 1967, participó en el movimiento estudiantil de mayo de 1968 y militó en el seno de la Internacional Situacionista (Internationale Situationniste) hasta principios de los años setenta ${ }^{30}$. Sólo adhiere a la CC en 1991, diez años después de haberse instalado como agricultor. Entre 1995 y 1999, este "neorrural", que cría ovejas en Lozère, en el sur de Francia, va a participar intensamente en la elaboración de una reflexión autónoma sobre la cuestión de los organismos genéticamente modificados (OGM). Este "intelectual", presentado como tal por otros activistas, se dedica a mostrar los intereses económicos en juego en la aplicación de esta innovación científica y a develar la ideología detrás del proyecto de "patentabilidad de lo vivo". En 1997 y 1998, apoyándose en esos argumentos, juega un papel motor en la organización de las primeras acciones del sindicato contra la utilización de semillas OGM en los cultivos.

Después de la reforma de la PAC de 1992, la dimensión internacional del combate sindical es utilizada en los debates internos por los activistas más favorables a un cuestionamiento

28 Informe de la reunión del Comité Nacional del 19 y 20 abril de 1994.

29 Association pour une Taxation des Transactions Financières et pour l'Aide aux Citoyens (Asociación por la Imposición de las Transacciones Financieras y por la Ayuda a los Ciudadanos).

30 Fundado en 1957, este movimiento literario y político realiza una crítica a la sociedad de consumo y a la "sociedad del espectáculo", según el título del trabajo publicado por Guy Debord en 1967. 
global del orden económico y social. Estas posturas activistas, autorizadas tanto por las trayectorias anteriores como por los desplazamientos de "lo internacional", son confortadas por el movimiento social de diciembre de 1995, por la movilización contra el Acuerdo Multilateral sobre las Inversiones (AMI), en $1998^{31}$ y, más ampliamente, por la dinámica contestataria de fines de los años noventa. Sintomáticamente, a partir de 1995 las posiciones adoptadas en el espacio público por el sindicato se radicalizan. Pero para no sobrestimar la influencia de los responsables nacionales más comprometidos en aquel proceso, cabe destacar el hecho de que ese "contexto" político entra en resonancia con la historia de esta izquierda campesina y, más precisamente, con la historia de sus relaciones con la izquierda que está en el gobierno, marcada por citas anuladas y decepciones. En el seno de la organización, la desconfianza colectiva respecto a las posiciones dominantes en el campo partidario tiende a aumentar las percepciones de las oportunidades políticas.

En agosto de 1999, las justificaciones de la acción de Millau se inscriben en una perfecta continuidad del informe de orientación redactado unos meses atrás, que afirma: "la OMC se ha transformado en el santuario de ese proceso en que los Estados, transformados en portavoces de las firmas multinacionales, tratan de imponer una visión uniformizante y reductora de los intercambios internacionales"32. Igualmente, en la primavera de 1999, el Comité Nacional incita a llevar a cabo acciones significativas para "aumentar la presión en la reunión cúspide de Seattle", en noviembre. Desde ese punto de vista, el "desmontaje" del McDonald's puede considerarse como una "acción nacional". Sin embargo, como hemos constatado durante nuestra encuesta, las estructuras departamentales de la CC tenían una real autonomía de decisión. Concretamente, esta acción sindical ha sido imaginada y organizada por los activistas del Aveyron. En consecuencia, corresponde presentar las condiciones específicas que han permitido el éxito formidable de esta acción "local".

\section{3. "Una acción como otras". Los activistas del Aveyron en agosto de 1999}

La realización de esta acción es consecutiva a una decisión tomada en julio de 1999, durante una reunión del Sindicato de Productores de Leche de Oveja (Syndicat des Producteurs de Lait de Brebis, SPLB). Esta estructura agrupa a activistas de la CC del Aveyron que venden leche de oveja a empresas especializadas en la fabricación de queso roquefort ${ }^{33}$. Para comprender lo que estaba en juego en esta acción, hay que detenerse, aunque sea brevemente, en la historia del SPLB.

En 1987, para terminar con la sobreproducción de leche de oveja, la Interprofesión Roquefort, que reúne a industriales y productores -representados por el Sindicato de Criadores

Acerca de esta movilización anti-AMI, véase el análisis de Daniel Mouchard (2005).

32 Informe de orientación del Congreso de Vesoul, abril de 1999, "Contre la dictature des marchés. Des paysans nombreux pour une Europe solidaire" (Contra la dictadura de los mercados. Numerosos campesinos por una Europa solidaria), p. 6.

33 La principal empresa de transformación se implantó "históricamente" en la aldea de Roquefort, situada en el sur del Aveyron, a unos kilómetros de la meseta de Larzac. 
de Ovejas (Syndicat d'Éleveurs de Brebis, SEB), afiliado a la FNSEA-, instaura un sistema de cuotas lecheras. Muy rápidamente, se crean Comités Roquefort que se oponen a la instauración de una política que fragiliza a las pequeñas explotaciones, que no son responsables de la sobreproducción. Estos Comités, que formarán la SPLB a principios de los años noventa, multiplican las acciones de protesta, pero la Interprofesión persiste en reconocer una sola organización de productores. En 1988, informados de la existencia de "fondos negros" (un sistema de financiamiento oculto), los activistas de los Comités inician una acción judicial contra la Interprofesión. Finalmente, en 1994, el SPLB "negocia" la suspensión de dicha acción a cambio de la presencia de dos representantes (uno de los cuales es José Bové) en el Consejo de Administración de la Interprofesión. Este acuerdo debía ser negociado a fines del año 1999. La acción de Millau debe ser relacionada con estos dos tipos de apuestas locales, que pueden distinguirse en el análisis pero que se confunden probablemente en las intenciones de los activistas: por un lado, el mantenimiento de numerosos productores, que se encontraban amenazados por la medida de sobreimposición adoptada por el gobierno americano y, por el otro, la lucha por la representatividad del SPLB en el seno de la Interprofesión y su búsqueda de legitimidad frente a los industriales y al SEB.

Este análisis localizado permite abordar otra pregunta: ¿en qué medida esta acción constituye un "acontecimiento" para los activistas que participan en ella? El 12 de agosto de 1999, los activistas de la CC del Aveyron y de los departamentos limítrofes están presentes, pero también los hay de otras organizaciones de izquierda de la región de Millau. Esta manifestación tiene éxito porque se inscribe localmente en una serie de acciones y de reflexiones comunes, que resultan de la formación de una red de relaciones activistas, formales e informales. El origen de esa red se sitúa en la lucha de Larzac contra la extensión de un campo militar (1972-1981) 34 . A principios de los años ochenta, "la lucha", victoriosa, se transforma en un símbolo. Los habitantes de Larzac se esfuerzan por transmitir su memoria, transformándola en un modelo - "la no-violencia activa"- que estiman transponible a otros movimientos de "resistencia"35.

Los activistas de la CC instalados en el sur del departamento ocupan una posición central en esa red activista. Desde principios de los años ochenta, han adquirido progresivamente una gran confianza en su capacidad de dirigir ese tipo de acciones. En 1999, ya han acumulado la experiencia de numerosas acciones espectaculares que han provocado a veces daños materiales y/o demandas judiciales ${ }^{36}$, de las que dio cuenta la prensa local y regional. Esta cultura de la confrontación sindical, del enfrentamiento físico y el gusto claramente asumido

34 En 1972, 103 campesinos instalados en la meseta de Larzac, directamente afectados por el proyecto de extensión del campo militar, se comprometen a no ceder nunca sus tierras al Estado. Rápidamente, son apoyados por diferentes movimientos políticos (maoístas, ecologistas, defensores del tercer mundo, regionalistas, etc.). En Francia, la lucha de Larzac es generalmente presentada como particularmente emblemática de la contestación de los "años 68". Véanse Martin (1987) y Alland (1995).

35 En los años ochenta, los "activistas Larzac" apoyaron a los independentistas de Nueva Caledonia (territorio de ultramar francés en Oceanía).

36 Para mayores detalles, remitimos al capítulo 7 de nuestra tesis doctoral (2006). 
por ese tipo de acción, no se encuentra, o se halla con menor intensidad, entre los activistas del norte y del oeste del Aveyron.

La especificidad del grupo del sur del Aveyron debe relacionarse con las trayectorias biográficas de sus miembros. Este grupo está compuesto esencialmente por "neorrurales", nacidos en los años cincuenta y sesenta. Algunos Ilegaron a la meseta de Larzac a finales de los años setenta, para ayudar a los campesinos en su lucha contra el ejército. Ése es precisamente el caso de José Bové. A principios de los años setenta, titular de un bachillerato, vive con su compañera en Burdeos. Siendo objetor de conciencia, milita en un movimiento antimilitarista. En 1976, la pareja se instala en la meseta de Larzac y ocupa una de las granjas compradas por el Estado. En 1981, después de la elección de François Mitterrand a la presidencia de la República, el abandono del proyecto de extensión del campo militar permite regularizar esas tomas "ilegales". Los otros miembros del grupo, un poco más jóvenes, no han participado directamente en "la lucha". Más frecuentemente, su llegada a la región de Millau, en los años ochenta, resulta de un proyecto de instalación como agricultores, a veces precedido por varias experiencias como asalariados en el mundo agrícola. Sin embargo, más allá de lo que puede distinguirlos, los "neorrurales" tienen en común el hecho de no tener que asumir la herencia de una posición social en la profesión.

Además, conviene insistir en la singularidad de la CC del Aveyron, que muy pronto, desde comienzos de los años noventa, y más frecuentemente que en otros departamentos, ha tratado de llamar la atención sobre las consecuencias de los Acuerdos del GATT. En noviembre de 1992, tiene la más fuerte representación en el grupo que penetra en la Bolsa de París para denunciar "el liberalismo integral". Otro ejemplo: en julio de 1993, durante la reunión cumbre del G7 en Tokio, ocupa la municipalidad de Rignac, una pequeña comuna del Aveyron cuyo alcalde, Jean Puech, es también ministro de Agricultura del gobierno de Balladur. El colectivo activista del Aveyron se consideró durante mucho tiempo "minoritario" en una organización nacional juzgada demasiado "tibia". Se entiende mejor por qué esos activistas han podido percibir en el momento "el McDo" como "una acción como otras", y no pensar que pudiera crear un impacto más importante que las anteriores.

Al inscribir el "desmontaje" del McDonald's de Millau en esta configuración original, se comprende cuáles fueron los resortes de la movilización nacional a favor de la "liberación" de José Bové durante las semanas siguientes. Antes de su detención "preventiva", unos quince activistas son interrogados por la policía y cuatro de ellos encarcelados durante tres días $^{37}$. Es la primera vez que la justicia reacciona con tanta dureza frente a una acción de este tipo. Los activistas que no fueron detenidos movilizan sus redes locales. Menos de una semana después del "desmontaje", se organiza una manifestación en Millau después de la cual las manifestaciones de apoyo a nivel nacional se multiplican. Consecutivamente al

37 José Bové, que está en ese momento de vacaciones, vuelve a Millau una semana después de las primeras detenciones. 
encarcelamiento de José Bové, la CC será mediatizada con una intensidad desconocida hasta entonces. Falta ahora analizar los diferentes procesos de adaptación a esta nueva situación.

\section{EL "SEGUNDO NACIMIENTO" DEL SINDICATO: BENEFICIOS IDENTITARIOS Y CRISTALIZACIÓN DE LAS DIVERGENCIAS}

Desde fines del año 1999, la intensa mediatización de las posiciones de la CC crea un sentimiento "eufórico" de pertenencia a colectivos activistas. En una segunda etapa, después de las elecciones profesionales de enero del 2001, algunos grupos locales comienzan a interrogarse sobre el contenido de los mensajes transmitidos y a evaluar su impacto sobre las percepciones que "los campesinos" pueden tener del sindicato. Este debate, a veces conflictivo, no invalida totalmente los beneficios que trae el reconocimiento del sindicato, pero obliga a los activistas a elegir entre diferentes estrategias de representación.

\subsection{Los activistas frente al espejo mediático: el tiempo de las retribuciones simbólicas}

Por regla general, los activistas se alegran de la irrupción de su sindicato en la escena pública. Adhieren a los comentarios periodísticos que sitúan su organización en el movimiento de oposición a la mundialización. Aunque algunos emitan reservas sobre la participación en programas de televisión, todos reconocen que José Bové tiene el mérito de haber terminado con el aislamiento: "hace tiempo que decimos lo que él dice, pero nadie nos escucha". Aceptan tanto más su dirección cuanto que era "Secretario Nacional en el momento de la creación de la CC en 1987" y que puede entonces expresarse legítimamente en su nombre. Esta izquierda campesina, marcada duraderamente por los acontecimientos posteriores a mayo de 1968, había tratado hasta ese momento de controlar la delegación del poder de representación. Sin embargo, la personalización del sindicato pasa a ser percibida como necesaria para llevar a cabo la difusión de sus reivindicaciones. A modo de ejemplo sintomático de las reacciones observadas durante este período, otro de nuestros entrevistados en septiembre del 2000 no disimulaba su entusiasmo con respecto al "fenómeno José Bové":

"Y tú, ¿qué opinas de lo que pasa en torno a Bové?

No conozco personalmente a José Bové, para nada, he leído una buena parte de su libro (Le monde n'est pas une marchandise, 2000), a mí me parece bien, yo hago un balance globalmente positivo, porque hacía falta alguien que pudiera cautivar a los medios, es cierto que teníamos tantas cosas que decir a nivel de la Confederación desde hace tanto tiempo y no conseguíamos decirlo, en ninguna parte, no nos tomaban en serio, éramos minoritarios. E hizo falta que José se transformase en 'vedette', bueno, ocurrió y tanto mejor, yo creo que eso le sirve a todo el mundo, y no sólo a la Confederación Campesina, eso sirve a muchos ciudadanos que tenían cosas que decir y las dicen, ése es el aspecto interesante, eso va a hacer evolucionar la política de otra manera, no es la política de los partidos políticos que vienen a convencer a la base, aquí tenemos la impresión que José Bové ha sido una tribuna que permite a la gente expresarse, cualquiera sea su sensibilidad política, se expresan sobre su vida, sobre lo que consumen, sobre su cultura, uno tiene la 
impresión que hay un efecto catalizador y eso es interesante, ¿no?, es interesante que la Confederación sea un poco el canal".

Esta mediatización, tanto más apreciable cuanto que nadie ya se la esperaba, hace ver y oír a los agricultores "de izquierda" preocupados por los desequilibrios norte-sur, perfectamente conscientes de los riesgos ecológicos y atentos a lo que viven otros grupos sociales. Esas imágenes coinciden con las identidades sociales que los activistas quieren encarnar, y en particular cuando reivindican su "apertura" en oposición al "encierro en sí mismo del mundo campesino". La crítica de las mentalidades y de la pesadez cultural típica del mundo agrícola no sólo la expresan los "neorrurales", sino que impregna también los comentarios de los hijos de agricultores. Esos "herederos" han sido generalmente socializados en fracciones culturalmente dominantes del mundo agrícola, tienen más diplomas que los agricultores de su generación y a veces han ejercido otros oficios antes de "volver" a la agricultura. Su ubicación a la izquierda o a la extrema izquierda es indisociable de su "desapego" simbólico del mundo agrícola ${ }^{38}$. En consecuencia, en la medida en que suscita interés y simpatía en medios sociales ajenos a su entorno profesional, la nueva notoriedad de la organización refuerza el distanciamiento respecto a las normas vigentes en el mundo agrícola y reactualiza las retribuciones simbólicas que fundan su compromiso en ese sindicato minoritario ${ }^{39}$.

\subsection{Cuestionamiento de "Io internacional": compromiso altermundialista y representación profesional}

Como ya hemos subrayado, el discurso altermundialista desarrollado por la CC después de la acción de Millau se inscribe en la prolongación de un proceso desencadenado por la reforma de la PAC en 1992. Sin embargo, las consecuencias de la acción de Millau refuerzan la legitimidad de "lo internacional". En abril del año 2000, en el Congreso de Argentan, en el que José Bové es elegido como miembro del Secretariado Nacional, François Dufour propone "respuestas globales" a "la ofensiva neoliberal". Delante del Ministro de Agricultura del gobierno de Lionel Jospin, el portavoz evoca la necesidad de "afrontar a las multinacionales ${ }^{\prime \prime 40}$ que, según él, son las principales beneficiarias de las políticas agrícolas. En el 2002, cuando la Comisión Europea hace públicas sus propuestas de reforma de la PAC, la CC considera que se trata de "la etapa terminal de una adaptación a las exigencias de la Organización Mundial del Comercio" ${ }^{\prime 41}$. El sindicato encabeza una campaña de protesta que desemboca en la redacción de una "plataforma" firmada por la CNJA, por asociaciones de consumidores y por numerosas organizaciones que actúan a favor de la protección del

38 Para un análisis más detallado de las trayectorias biográficas, ver nuestra tesis (2006), en particular la segunda parte: "A 'juste' distance des paysans. Position sociale dans le monde agricole et militantisme à la Confédération Paysanne" ("A 'justa' distancia de los campesinos. Posición social en el mundo agrícola y activismo en la Confederación Campesina").

39 Acerca de las retribuciones simbólicas de la militancia, véase Gaxie (1977, 2005).

40 Apuntes de terreno tomados ese mismo día.

41 "Pour une PAC au service des paysans et des citoyens" (Por una PAC al servicio de los campesinos y los ciudadanos), documento difundido a fines del 2002. 
medio ambiente y de la solidaridad internacional. En suma, la importancia acordada a la lucha contra la OMC necesita un trabajo de explicación, que da lugar a la producción de textos pedagógicos destinados a un amplio público de activistas ${ }^{42}$.

Paralelamente, esta efervescencia altermundialista modifica las relaciones de fuerzas internas, al volver temporalmente indiscutibles las posiciones "movimientistas" así como "internacionalistas". Durante los años 1999-2002, las posiciones que eran marginales diez años antes son consagradas y los activistas que las encarnan acceden más fácilmente a puestos de responsabilidad. En el 2001, el Secretariado Nacional, compuesto en esa época por nueve miembros, comprende cuatro "neorrurales" instalados en el sur de Francia, todos marcados por un compromiso con la extrema izquierda en los años setenta. Régis, activista de la CC del Aveyron, reconoce que esta dinámica colectiva ha sido determinante en su decisión de postular al Secretariado Nacional: "ingresé en ese momento, no por casualidad, fue después de la acción del Mc Do, yo era uno de los diez inculpados, de los que han sido encarcelados al principio y entonces en un momento dado sentí que podía aportar mi piedra al edificio, y me acerqué naturalmente...". Más allá de las convergencias políticas, predomina en la estructura nacional una manera específica de militar en la CC, caracterizada por el rechazo de todo compromiso con el gobierno y por una gran confianza en la eficacia de las acciones mediáticas. Esos activistas son también los más favorables a la constitución de un "movimiento social". Los numerosos procedimientos judiciales a los que debe hacer frente el sindicato durante ese período le otorgan la oportunidad de solicitar el apoyo de organizaciones situadas "a la izquierda de la izquierda" y de establecer relaciones duraderas con las organizaciones de las que se siente más cerca: Derecho al Alojamiento (Droit au Logement), la Asociación de Cesantes (Association de Chômeurs, AC!), el sindicato SUD.

En las elecciones a la Cámara de Agricultura ${ }^{43}$ de enero del 2001, la CC recoge el $26 \%$ de los sufragios expresados y gana seis puntos respecto al escrutinio precedente. Con el $53 \%$ de los votos, la coalición FNSEA-CNJA continúa siendo ampliamente mayoritaria, pero pierde seis puntos con respecto a 1995. Esas elecciones confirman la progresión de la "representatividad" nacional de la CC. La cifra de $26 \%$ es un promedio nacional que oculta diferentes relaciones de fuerza según los departamentos. La CC obtiene por lo menos 30\% de los votos en más de treinta departamentos, y por lo menos 35\% en otros quince. En las regiones del este y del sur del país, varias estructuras departamentales conocen un alza espectacular. En cambio, en las regiones del oeste, los resultados del sindicato se estancan o disminuyen. Así, en el departamento del Finistère (Bretaña), la CC, cuyo puntaje es inferior en veinte puntos al de $1995^{44}$, pierde la gestión de la Cámara de Agricultura. En esas zonas de implantación "histórica" de la izquierda campesina, los activistas, confrontados a un veredicto que pone

42 Véase por ejemplo Changeons de politique agricole (Cambiemos la política agrícola) (2002).

43 Presentes en cada departamento, las Cámaras de Agricultura son organismos públicos que trabajan en aplicar las orientaciones de la política agrícola del gobierno. Su gestión está asegurada por el sindicato que recoge la mayor cantidad de sufragios en las elecciones profesionales, cada seis años.

44 Después de las elecciones de enero del 2001, la CC sólo controla una sola Cámara de Agricultura, la del departamento de Loire-Atlantique. 
fin a una dinámica electoral iniciada a principios de los años ochenta, tratan de identificar las causas del fracaso. Expresan reservas sobre la capacidad de los organismos dirigentes a nivel "nacional" de "movilizar a los campesinos" y se interrogan especialmente sobre la acogida de una campaña mediática que ha consistido esencialmente en las intervenciones de José Bové. En esos mismos departamentos, los activistas se preguntan si los agricultores pueden verdaderamente interesarse en lo que pasa en la OMC, ya que están sobre todo preocupados por las fluctuaciones del precio de la leche o por las compensaciones prometidas después de la "crisis de la vaca loca". Lamentan que la expresión "malbouffe" (mala comida), utilizada por José Bové después de la acción de Millau, haya sido tan a menudo transmitida por los medios, pues no les habría caído muy bien a los agricultores ser así estigmatizados. Por último, las posiciones tomadas por José Bové a propósito del conflicto israelí-palestino, ampliamente comentadas en la prensa, habrían contribuido a confundir la imagen de la CC, cuando un sindicato no puede permitirse estar asociado a asuntos políticos de esta índole.

En el 2002, esas críticas puntuales y finalmente bastante heterogéneas condujeron a ciertas "figuras" del sindicato a criticar la orientación del Secretariado Nacional. En la Asamblea General de Créteil, dieciséis antiguos responsables nacionales proponen una serie de nueve enmiendas al Informe moral. La mayoría de ellos ha tenido responsabilidades en la organización a finales de los años ochenta y principios de los años noventa, en un período en que su "estructuración", todavía balbuciente, era "prioritaria". Desde su punto de vista, la constitución de un "movimiento social" alejó al sindicato del mundo agrícola: "Nuestros combates campesinos deben conservar su dimensión ciudadana. Pero no son los no campesinos los que pueden definir o dictar la política agrícola; son los campesinos

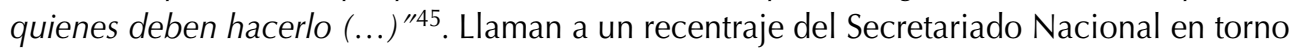
a las misiones originales de la CC, es decir, la defensa de los "pequeños agricultores" y la promoción de una "agricultura campesina" mediante la valorización de prácticas alternativas. Estiman que a pesar del impacto de las políticas agrícolas transnacionales, los lugares de decisión a nivel nacional (gobierno) y departamental (Cámaras de Agricultura) dejan un margen de maniobra. Los miembros del Secretariado Nacional les responden que "solamente un cambio significativo de la política agrícola a nivel internacional" (PAC y OMC) permitirá la realización de los objetivos del sindicato. La iniciativa de los antiguos responsables nacionales provoca fuertes tensiones en el seno de la organización. Las enmiendas son mal recibidas por el equipo dirigente, algunos considerándolas "una provocación", otros "una declaración de guerra" o "una tentativa de desestabilización". Sin embargo, a fines del año 2002, aceptan abrir el debate sobre las orientaciones estratégicas del sindicato, solicitan a las estructuras departamentales que tomen posición mediante la redacción de una "contribución" y fijan la convocatoria de una Asamblea General "extraordinaria" a principios del 2003. El 14 de enero, un centenar de delegados se reúne en Bagnolet para crear las condiciones que permitirán resolver la crisis. Las intervenciones revelan la magnitud de los desacuerdos entre las dos "tendencias" más claramente identificables. Un miembro

45 Enmienda $\mathrm{N}^{\circ} 3$, "Propositions d'amendements au Rapport moral" (Proposiciones de enmienda al Informe moral), Asamblea General de Créteil, 3 y 4 abril del 2002. 
del Secretariado Nacional afirma por ejemplo que "el statu quo no es viable, ya que ciertas personas ya no quieren trabajar juntas" $" 46$. Al final del día, la mayoría de los delegados rechaza las dos mociones preparadas por las tendencias en conflicto y se pronuncia en favor de una moción intermedia. Cuatro meses después, en abril del 2003, en el Congreso de Vendôme, las tensiones no se han apaciguado completamente, pero los activistas parecen dispuestos a retomar el diálogo. Al final del Congreso, la composición del nuevo Secretariado Nacional, elegido por el Comité Nacional, ratifica los resultados del debate organizado en Bagnolet. Cuatro activistas, que aparecen claramente como los representantes de una línea política favorable a una modificación de las posiciones de la CC, ingresan al Secretariado Nacional.

El debate nacional tomó la forma de una reflexión colectiva para encontrar el mejor compromiso posible entre la interpelación de la "opinión pública", que debía supuestamente atenuar la posición "minoritaria" de la CC en el terreno profesional, y el trabajo de sensibilización de los agricultores, condición necesaria para que el poder político tomara en cuenta sus reivindicaciones. Más allá de las divergencias explícitas, anunciadas en términos estratégicos, ese momento de cristalización revela la existencia de un conflicto de representaciones implícitas, suerte de percepciones cruzadas que determinan la capacidad de cada uno de representar de la mejor manera posible al sindicato y a los que lo componen. Los activistas evalúan esta competencia identificando "estilos políticos" -definidos por la apreciación de las posiciones individuales, no estrictamente sindicales, y la manera en que parecen expresarse y encarnarse (lenguaje, hexis corporal)- para determinar si se adecúan con las funciones que asignan a la CC. Esas diferencias pueden explicarse por divisiones anteriores -algunas personas que han firmado las enmiendas de Créteil han tratado probablemente de retomar el conflicto que había dividido la estructura nacional a principios de los años 1990-, pero deben sobre todo ser referidas a las trayectorias biográficas de los activistas implicados en mayor grado en esta lucha interna. En efecto, la distinción entre los "herederos" y los "neorrurales", que parece ser decisiva en las posiciones relativas al compromiso altermundialista del sindicato, se explica por la naturaleza de las diferencias, a veces ínfimas, que distinguen sus procesos de politización, llevados a cabo bajo la influencia de acontecimientos posteriores a mayo de 1968. A diferencia de los "herederos", los "neorrurales" se sitúan a la izquierda o extrema izquierda del espectro partidista, a pesar de evolucionar en esferas sociales ajenas al mundo agrícola. Aunque provengan de familias conservadoras o de izquierda, no tuvieron que soportar ni transgredir las normas políticas vigentes en la profesión agrícola. Por regla general, esos "nuevos campesinos" deben su instalación en la agricultura a su inscripción previa en redes de sociabilidad militante. En oposición con ciertas interpretaciones relativas al movimiento de "regreso a la naturaleza" de los años setenta ${ }^{47}$, es "por medio de la política" que descubren más frecuentemente esta oportunidad profesional y no rehuyendo de sus compromisos anteriores. Las diferencias

46 Apuntes de terreno tomados ese mismo día.

47 Durante los años setenta, estudiantes y jóvenes asalariados abandonan las grandes ciudades y se instalan en las zonas rurales del sur de Francia, tratando así de escapar de las relaciones sociales condicionadas por el sistema capitalista. Véase Hervieu-Léger (1979). 
entre las trayectorias biográficas producen sus efectos más distintivos a fines de los años noventa, cuando la emergencia de un "movimiento social" obliga a arbitrajes entre identidad "política" (ser activista de la izquierda antiliberal) e identidad "profesional" (ser representante de la profesión agrícola). Además, entre 1997 y 2002, esas formas de ser activistas de la CC, trabajadas por un sentimiento de pertenencia al mundo agrícola de intensidad variable, son puestas a prueba por el contexto político nacional. La política agrícola del gobierno de "la izquierda plural" (dominada por el Partido Socialista) objetiva los desfases entre las formas que toma el distanciamiento con la izquierda institucional y acentúa la diversidad de los modos de representación del sindicato.

Sin embargo, no hay que reducir el análisis de las posiciones tomadas respecto a "lo internacional" a una estricta oposición entre "herederos" y "neorrurales". Para tomar un solo ejemplo, entre el 2000 y 2003, siendo miembro del Secretariado Nacional y portavoz de la CC sobre las cuestiones europeas, Jean-Pierre fue uno de los más fervientes promotores de la línea altermundialista. Sin embargo, este activista no es un "neorrural", sus padres eran agricultores en el departamento del Orne (Baja Normandía) y él retomó la explotación de su tío en 1973, antes de participar localmente en la construcción de una organización sindical autónoma. Elegido miembro del Comité Nacional en 1994, miembro de la oficina ejecutiva de la CPE desde 1995, Jean-Pierre se especializó progresivamente en políticas agrícolas internacionales. Frente a interlocutores tan diversos como los representantes de sindicatos extranjeros, los diputados del Parlamento Europeo o el Comisario Europeo de Agricultura, adquirió una competencia específica que le permite sentirse capaz de expresarse sobre lo que está en juego a nivel internacional. A partir de 1999, en esta nueva coyuntura que tiende a acreditar el discurso de la CC, ese "capital activista"48 es actualizado en situaciones públicas que crean las condiciones de una afirmación de sí mismo (mítines, conferencias de prensa, etc.). De una manera general, para Jean-Pierre como para los otros activistas, las lógicas de posicionamiento en el debate abierto en el 2002 deben relacionarse con los recursos acumulados durante sus carreras en el seno de la organización, puesto que las diferentes etapas de esas carreras individuales corresponden a momentos precisos en la historia interna del sindicato.

Al término de este análisis, no cabe duda que la acción efectuada el 12 de agosto de 1999 constituye un "acontecimiento". El éxito de esta acción, sus consecuencias judiciales, la emergencia de un portavoz eficaz, abren un nuevo período en la historia de la CC. Es a la vez "en" y "por" el encadenamiento de circunstancias, que el sindicato deviene altermundialista. Lo que nuestro análisis muestra es que la apreciación del acontecimiento depende en primer lugar de la experiencia de quienes lo viven. Desde fines de 1999, los activistas que han previamente tratado de imponer el significado del acontecimiento dentro y fuera de la organización se esfuerzan en "recrearlo" y por ende en hacerlo fructificar mediante acciones y tomas de posición que prolongan el momento altermundialista de la CC. Inversamente, en el 2002, un grupo de antiguos responsables nacionales, actuando como

48 Véase Matonti y Poupeau (2004). 
depositarios de la historia del sindicato, trataron de "contener" los efectos del acontecimiento mediante una interpretación "realista" de la situación. Esas maneras de posicionarse en los debates internos dependen en gran parte del modo en que los activistas han participado en el trabajo de redefinición de "lo internacional" en el curso de los años noventa. Es en efecto después de la reforma de la PAC de 1992 cuando aparecen las primeras lógicas de diferenciación que originan el proceso de radicalización observado a fines de los años noventa. Podrían encontrarse probablemente mecanismos análogos en la historia reciente de las otras organizaciones del movimiento altermundialista, bajo la forma de deslizamientos en el ejercicio de responsabilidades internas provocadas por las percepciones de un nuevo "contexto" político. En síntesis, esta historia de los usos internos de "lo internacional" muestra hasta qué punto resulta interesante multiplicar las fuentes -el conflicto de principios de los años noventa no había sido objeto de ningún tratamiento periodístico-, observar los momentos de reunión de colectivos -sorprendentemente, las tensiones de los años 20022003 no trascendieron a la luz pública- y "localizar" las prácticas militantes. La CC del Aveyron, debido a su historia particular, era probablemente la única estructura departamental susceptible de llevar a cabo esta acción "simbólica" contra el McDonald's y de justificarla poniendo en relación "lo local y lo global".

\section{ACRÓNIMOS}

AC!: Agir Ensemble Contre le Chômage (Actuar Juntos en Contra de la Cesantía).

AMI: Acuerdo Multilateral sobre las Inversiones.

ATTAC: Association pour une Taxation des Transactions Financières et pour l'Aide aux Citoyens (Asociación por una Imposición de las Transacciones Financieras y por la Ayuda a los Ciudadanos).

CC: Confédération Paysanne (Confederación Campesina).

CEE: Comunidad Ecónomica Europea.

CNJA: Centre National des Jeunes Agriculteurs (Centro Nacional de Jóvenes Agricultores).

CNSTP: Confédération Nationale des Syndicats de Travailleurs Paysans (Confederación Nacional de Sindicatos de Trabajadores Campesinos).

CPE: Coordination Paysanne Européenne (Coordinación Campesina Europea).

FNSP: Fédération Nationale des Syndicats Paysans (Federación Nacional de Sindicatos Campesinos).

FNSEA: Fédération Nationale des Syndicats d'Exploitants Agricoles (Federación Nacional de Agricultores).

GATT: General Agreement on Tariffs and Trade (Acuerdo General sobre los Aranceles y el Comercio).

OGM: Organismos Genéticamente Modificados.

OMC: Organización Mundial del Comercio.

PAC: Política Agrícola Común.

SEB: Syndicat d'Éleveurs de Brebis (Sindicato de Criadores de Ovejas).

SPLB: Syndicat des Producteurs de Lait de Brebis (Sindicato de Productores de Leche de Oveja). 


\section{BIBLIOGRAFÍA}

Agrikoliansky, Eric, Olivier Fillieule y Nonna Mayer (dir.) (2005): L'altermondialisme en France. La longue histoire d'une nouvelle cause, Flammarion, París.

Agrikoliansky, Eric y Boris Gobille (2011): "El activismo altermundialista en Europa. Problemas de análisis y resultados recientes", Revista de Sociología, 25, pp. 139-161.

Alland, Alexander Jr. (1995): Le Larzac et après. L'étude d'un mouvement social novateur, L'Harmattan, París.

Bensa, Alban y Eric Fassin (2002): "Les sciences sociales face à l'événement", Terrain, 38, pp. 5-20.

Bourdieu, Pierre (1971): "Genèse et structure du champ religieux", Revue Française de Sociologie, XII, pp. 295-334.

Bové, José y François Dufour (2000): Le monde n'est pas une marchandise, La Découverte, París.

Bruneau, Ivan (2004): “La Confédération Paysanne et le 'mouvement altermondialisation'. L'international comme enjeu syndical, Politix, 68, pp. 111-134.

(2006): La Confédération Paysanne: s'engager à "juste" distance, Tesis de Doctorado en Ciencia Política, Universidad Paris X-Nanterre.

(2008): "Quand des paysans deviennent 'soixante-huitards'”, en Dominique Damamme, Boris Gobille, Frédérique Matonti y Bernard Pudal (dir.): Mai-Juin 68, Éditions de l'Atelier, París, pp. 344-356.

Confédération Paysanne (2002): Changeons de politique agricole, Mille et Une Nuits, París.

Contamin, Jean-Gabriel (2005): "Les grèves de décembre 1995: un moment fondateur?", en Eric Agrikoliansky, Olivier Fillieule y Nonna Mayer (dir.): L'altermondialisme en France. La longue histoire d'une nouvelle cause, Flammarion, París, pp. 233-263.

Dobry, Michel (1992): Sociologie des crises politiques. La dynamique des mobilisations multisectorielles, Presses des Sciences Po, París.

Foucault, Michel (2001): "Nietzsche, la généalogie, I'histoire", en Dits et écrits, Colección Quarto, Tomo I, Gallimard, París, pp. 1004-1024.

Fouilleux, Eve (2003): La Politique Agricole Commune et ses réformes. Une politique à l'épreuve de la globalisation, L'Harmattan, París.

Gaxie, Daniel (1977): “Economie des partis et rétributions du militantisme”, Revue Française de Science Politique, 27 (1), pp. 123-154.

(2005): "Rétributions du militantisme et paradoxes de I'action collective", Revue Suisse de Science Politique, 11 (1), pp. 157-188.

Lambert, Bernard (1970): Les paysans dans la lutte des classes, Seuil, París.

Léger, Danièle y Bertrand Hervieu (1979): Le retour à la nature. "Au fond de la forêt... I'Etat", Seuil, París. Martin, Didier (1987): Le Larzac. Utopies et réalités, L'Harmattan, París.

Matonti, Frédérique y Franck Poupeau (2004): "Le capital militant. Essai de définition", Actes de la Recherche en Sciences Sociales, 155, pp. 5-11.

Mouchard, Daniel (2005): "Le creuset de la mobilisation anti-AMI de 1998", en Eric Agrikoliansky, Olivier Fillieule y Nonna Mayer (dir.): L'altermondialisme en France. La longue histoire d'une nouvelle cause, Flammarion, París, pp. 317-337. 
Offerlé, Michel (1997): Les partis politiques, Colección Que sais-je?, tercera edición, PUF, París.

Snow, David (2001): "Analyse de cadres et mouvements sociaux", en Daniel Cefaï y Danny Trom (dir.): Les formes de l'action collective. Mobilisations dans les arènes publiques, Editions de I'EHESS, París, pp. 27-49. 


\section{Normas editoriales}

Para enviar artículos a la Revista de Sociología, los interesados deben cautelar los siguientes procedimientos y normas editoriales:

1. Enviar tres copias impresas, una de las cuales debe contener la identificación del autor con la indicación de un breve currículum: grado académico y ocupación. Además de las copias impresas, se debe incluir un respaldo electrónico del artículo en un CD.

2. La primera hoja de cada artículo debe contener: título, un resumen escrito en inglés y otro en español, que no supere las ciento veinte (120) palabras cada uno, e indicación de al menos tres palabras clave.

3. La extensión de cada artículo no debe superar las diez mil (10.000) palabras. Estos deben ser presentados en formato Word, interlineado doble y letra Times New Roman tamaño 12.

4. Los cuadros y gráficos deben ser presentados en un anexo o apartado final, indicando al interior del texto el lugar de su inserción.

5. Las citas deben ser presentadas entre paréntesis, indicando el apellido del autor y el año de edición del libro o artículo (Offe, 1990; Habermas, 1997). Se debe indicar la página en el caso de referencias y citas textuales (Rosanvallon, 2007: 45).

6. Especificar y numerar los títulos principales al interior del texto, estableciendo un sistema de distinción respecto de los subtítulos y otros apartados.

7. Al final del texto se debe incorporar el listado de la bibliografía citada, indicando el apellido y el nombre del autor, el título del libro o artículo (en cursivas para el caso de libros y entre comillas para el caso de artículos y capítulos), editorial, lugar y año de edición.

Los artículos deben ser enviados a nombre de Comité Editorial de la Revista de Sociología, Departamento de Sociología, Facultad de Ciencias Sociales, Universidad de Chile. Ignacio Carrera Pinto 1045, Tercer Piso, Ñuñoa, Santiago de Chile. Fono: (0056 2) 9787781 - 978 7782. Fax: (0056 2) 9787777.

Contacto: revsoc@uchile.cl 

ANDROS IMPRESORES

www.androsimpresores.cl 
